\title{
Proceeding
}

Supplementary Issue: Autumn Conferences of Sports Science. Costa Blanca Sports Science Events, 18-19 December 2020. Alicante, Spain.

\section{The impact of descending pyramid training size in development of the special strength of the arms and the accuracy of set shot in the wheelchair basketball player}

\author{
AHMED AMER MOHAMMED ALI \\ Department of Students Activities, Babylon University, Iraq
}

\begin{abstract}
The importance of this study lies in the use of descending pyramid training and the scope of its effect in developing the endurance of the two arms in all their different forms and the set shot accuracy for basketball players on wheelchairs. The researcher attempts to scientifically improves the sport level through the use of means of descending pyramid training whose use has become common among athletic players. The problem of the study is present in the weakness of the physical abilities in general and special strength in particular. This is reflected in the accuracy of set shot of the basketball players on wheelchairs. The problem is also lying in overcoming slow development in this strength which happens in wheelchair basketball players according to the type of disability and its severity which hinders the development of the sport performance. The researcher uses the experimental method in one group in the pre- and post-test. The population of the study is eleven male basketball players of the Maysan Governorate. The sample is selected according to comprehensive inventory method representing. After determining the tests and conducting the pre-tests, the training program is applied for six weeks, two units per week. After the application of post-tests and finding the results, the tests are analysed statistically, and the following results are found: the descending pyramid training improves the special strength and set shot for those players. The results show that there is a big effect and a significant level of this type of training for the development of all discussed variables. The researcher recommends necessarily the use of descending pyramid training to develop the forms of muscle strength during the general preparation of the team.
\end{abstract}

Keywords: Pyramid training; Special strength; Set shot.

\section{Cite this article as:}

Ali, A.A.M. (2021). The impact of descending pyramid training size in development of the special strength of the arms and the accuracy of set shot in the wheelchair basketball player. Journal of Human Sport and Exercise, 16(2proc), S499-S507. doi:https://doi.org/10.14198/ihse.2021.16.Proc2.34

Corresponding author. Department of Students Activities, Babylon University, Iraq.

E-mail: hussenabdmalrahm@yahoo.com

Abstract submitted to: Autumn Conferences of Sports Science. Costa Blanca Sports Science Events, 18-19 December 2020. Alicante, Spain.

JOURNAL OF HUMAN SPORT \& EXERCISE ISSN 1988-5202

(c) Faculty of Education. University of Alicante

doi:10.14198/jhse.2021.16.Proc2.34 


\section{INTRODUCTION}

The concept of sport expanded, and its importance increased. This is because the acquired experience interferes with other sciences through practicing, and scientific applications and research which lead to raise the level of sport through competition and achievement.

To reach the peak of achievement in the champion in any sport activities is linked with connected and complete chains of procedures and steps. These procedures and steps are built on scientific bases and subjective means to improve the process of practicing and highlight the qualifications of player to value the physical abilities. This is because they are important in different fields such as medicine and physiology (Abdul-Majeed, 1999:158).

The descending pyramid training related training is considered an economic process which saves time and effort. It achieves the best results and come with the best players in terms of physical, technical, psychological, and physiological abilities. This helps to improve performance because "the pyramid training and the ideal interval relax leads to achievement" (-Majeed, 1997:363).

Because of the characteristics of wheelchairs basketball among other sports for disabled, specialists most often work to find the best training means to develop the specific physical abilities and elevate their level in all of the physical elements required to arrive at high levels and achieve better results. It becomes clear that the high level cannot be achieved unless the specific physical abilities which the game requires are developed.

Looking at the wheelchairs basket balls in physical terms, we can see that special strength is the main feature in forming physical fitness. If a player wants to excel in the physical performance and in skills, one should have physical fitness in one way or another particularly s/he depends on the arms in playing. This is not achieved if there are no trainings for the special strength without neglecting other elements for physical fitness such as speed, endurance, flexibility, fitness, harmony, precision etc. These elements contribute to any skills or physical activities.

The forward performance in general and shot in particular require harmony in form the skill and specific physical perspective and this does not happen unless training courses aiming to improve types of special force of the arms are prepared. Therefore, it is necessary to exert effort and invest time to master the skills of shot and increase its precision through developing this force particularly because the results of the match depend on the how well the physical requirements of shot are mastered which are related to the game under the accompanying circumstances. This reflects the importance of this study in using descending pyramid training and the scope of its effect in improving all special force of the arms and the precision of set shot performance. The researcher tries scientifically to improve the level of sport through the use of pyramid training which has become popular among the athletes.

The development depending on the existence of the physical abilities and elements gives the skill full performance continuity without decreasing its level. This causes a lot of problems facing players and trainers in the training process which require scientific solutions. In addition, the training process experience problems related to the type of training. These processes are tools to organizes the distribution of the constituents of the load in the form which is suitable to the nature of game to better invest energy to achieve better results. 


\section{Problem}

There problems of the study are as follows:

1. The weakness of the physical abilities in general and special strength in particular negatively affect the precision of shot by the wheelchairs basketball players.

2. Overcoming slow progress cases in special strength. These cases happen to those players according to type and degree of disability which hinders the development level in sport.

3. Many trainers ignore this type of training in the athletics particularly those working in the field of disabled athletes.

\section{Aims}

The study aims are:

1. Showing the effects of the descending pyramid training on the special strength of the arms and the precision of set shot by the wheelchairs basketball players.

2. Revealing the effects of descending pyramid training on the special strength and set shot by the players.

\section{Hypotheses}

The study hypothesizes the followings:

1. There are mean differences, indicated by statics, between pre- and post-tests in the descending pyramid training for the development of special strength of the wheelchairs basketball players. The differences are positive in the post-tests.

2. There are mean differences, indicated by statics, between pre- and post-tests in the descending pyramid training for the development of set shot of the wheelchairs basketball players. The differences are positive in the post-tests.

\section{Scope}

The study sample includes players of the wheelchairs basketball team of Maysan from 7-3-2019-25-4-2019 in the gym of lifting weights and The Closed Para Olympic Hall in Maysan.

\section{METHOD}

The researcher uses the experimental one group method of pre- and post-tests.

\section{Sample}

The population of the study is eleven basketball players from the Maysan Governorate. The sample selected consists of eleven male players by the use of comprehensive inventory representing all the individuals of the society.

\section{Tools and Equipment}

The study employs the following:

1. Arabic and English references.

2. The internet.

3. Statistics software (SPSS).

4. The legal basketball stadium.

5. Four legal basket balls.

6. Wheelchairs for the disabled (spin off) made in Italy.

7. Two medical balls $(1.5 \mathrm{~kg})$. 
8. A lifting weigh terrace for the disabled.

9. Legal weights of different sizes and weights $(0.25$ to $25 \mathrm{~kg})$.

10. Three legal saws.

11. One timer clock.

12. Four nylon adhesive belts of width $8 \mathrm{~cm}$ to tie the legs and thighs.

\section{Method of testing}

Following studying, surveying, the experience of the researcher and with the help of the specialists, the researcher arrives at the assumption that the best method of testing is using athlete testing on the wheelchairs and medical ball because it indicates a high authenticity, consistency and objectivity in the tests for many reasons:

1. The sample differs in itself in terms of endurance and performance

2. The use of wheelchair athlete testing, and medical ball are used because it is suitable with the performance skills in the competitions. Thus, the following tests are set:

The test of explosive power

A ball of $1.5 \mathrm{~kg}$ is thrown by the two hands from behand the head in the sitting posture on the wheel Charis for the farthest distance possible (Al-lbrahim.2007:91).

The test of mobility speed

Running by the wheelchairs for $15 \mathrm{~m}$ of movement (Al-lbrahim.2007:92).

The test of endurance (Ali, 2013:75)

The test of set shot (Ibid: 85)

\section{Survey study}

It is the first study the researcher conducts on a small sample to assure the validity of the tests and deals with errors they face while doing the test to avoid them in the study. This study was done on 27/3/2109 at 10 am applied on one player from the sample.

Trainings and Tests used in the study

The number of trainings according to the new method is two per week and 30-40 minutes for each.

The number of training in the experimental study is twelve.

The Pre-Tests for the experimental group

The pre-tests were conducted on 14/3/2019 at 10 am in The Para Olympic Hall in Maysan.

The Post-Tests

Following the completion of the experimental study, the researcher conducts the post-tests on the sample on 25/4/2019 at 10 am in the same hall in which the pre-tests were done. The differences of time, space, means and tool which are the same are considered in the pre- and post-tests as much as possible.

\section{Statistics methods}

SPSS is used to gain the results according to the following statistics rules:

1. Arithmetic mean. 
2. Standard deviation.

3. The simple correlation coefficient Pearson.

4. Tests $(\mathrm{t})$ for the Dependent Samples.

5. Pearson law to find the size of effect.

\section{RESULTS, ANALYSIS AND DISCUSSIONS}

\section{Results, analysis and discussion of the special strength and set shot}

Table 1 below explains the arithmetic means, the pre- and post- standard deviations, the calculated t value for the experimental group of special strength and set shot for wheelchair basketball players.

Table 1. Arithmetic mean, pre- and post-standard deviation, calculated $t$ value, and studies level of significance.

\begin{tabular}{|c|c|c|c|c|c|c|c|c|}
\hline \multirow{2}{*}{$\begin{array}{l}\text { Studies } \\
\text { variable }\end{array}$} & \multirow{2}{*}{$\begin{array}{l}\text { Unit of } \\
\text { measure }\end{array}$} & \multicolumn{2}{|c|}{ Pre } & \multicolumn{2}{|c|}{ Post } & \multirow{2}{*}{ Value $\mathrm{t}$} & \multirow{2}{*}{$\begin{array}{l}\text { Level of } \\
\text { Significance }\end{array}$} & \multirow{2}{*}{$\begin{array}{l}\text { Mean } \\
\text { Difference }\end{array}$} \\
\hline & & $S$ & $A$ & S & A & & & \\
\hline Explosive power & metro & $3 / 715$ &.$/ 935$ & $4 / 619$ & $0 / 904$ & $3 / 171$ & $0 / 010$ & Mean \\
\hline Mobility speed & second & $5 / 539$ & $1 / 211$ & $4 / 464$ & 0/890 & $3 / 306$ & 0/008 & Mean \\
\hline endurance & minute & $3 / 654$ & $0 / 829$ & $3 / 22$ & 0/736 & $6 / 095$ &.$/ 000$ & Mean \\
\hline Set shot & point & $7 / 36$ & $2 / 275$ & $8 / 909$ & $1 / 758$ & $2 / 424$ & 0/036 & Mean \\
\hline
\end{tabular}

The table above shows that there are differences in mean values for all the variables. This indicates there are real mean differences between pre- and post-testes when doing the studies tests.

The arithmetic mean for the explosive power for the pre-test is 3.715 with standard deviation 0.935 , while the arithmetic mean for the post test is 4.619 with a standard deviation 0.904 . To know the mean change benefits which of the tests, the researcher uses $t$ value for the independent samples from which the results come referring to the existence of real mean differences. That is because the calculated t value for them is 3.171 at the level of significance of .010 . Thus, the statistical significance is mean and supports the post-test.

The researcher could attribute the mean differences to the nature of wheelchair basketball and the type of exercise which the players conduct using weights according to the continuous descending pyramid.

"Continuing on the same weights preserves the acquired adaptations and does not develop them. Hence, the need for training using a new weight emerges. The used increase of weight is considered an example for the principle of gradual development' (Al-Qit, 1990:36). Also, the weight practice targeting a specific group of muscles leads to change them (Abdel-Khaleq, 1999:107).

The arithmetic means to select the pre- mobility speed is 5.539 with a standard deviation 1.211 while he arithmetic mean to select the post- mobility speed is 4.464 with a standard deviation 0.736 . For the purpose of finding which test do the change positively affect, the $t$ value for the independent samples is used from which the results indicate the existence of real mean difference. That is because the calculated t value at level of significance .008, therefore the change benefits the post-test. This could be because the executed course by the researcher for 6 weeks, two each week and using training weights suitable to the ability of each player in the experimental group and this affect in terms of mean the physical abilities in the post test.

Al-Basaty states "to develop the mobility speed, the coach must make sure the existence of a level of power and speed before launching these types of trainings and the performance happens intensity less than the 
peak with speed at the same time" (2001:94). This is done to the sample of the study; they were informed of these physical abilities before executing the course according to that.

Also, the ability to quickly fill the largest number of muscle fibres at the beginning of the movement is an important characteristic for developing strength characterized by speed. Therefore, high-resistance exercises should be performed at the beginning of the movement, then reduced resistance at the next stage (AbdelFattah, 1997: 134).

The researcher believes that the transition in the use of the largest possible number of kinetic units at the beginning of the exercise and then the moving to the lower use in the lower intensity gives a period for recovery of the kinetic units used at the beginning of the exercise. This makes these units work more efficiently when moving to the second exercise.

The arithmetic mean is 3.654 for the endurance capacity of the pre-test and a standard deviation of 0.829 . The arithmetic mean for the post-test is 3.22 is with a standard deviation of 0.736 . To determine the change benefit goes to which tests, the researcher uses the $(t)$ test for the independent samples. Hence, the results indicate the presence of a real and significant difference because the calculated $T$ value of them reaches 6.095 at the level of significance of .000 so the statistical significance benefits the-post test.

The researcher could attribute the benefit of the change to the fact that the continuous descending pyramid has affected this physical ability. In addition, the scientific sources indicate that there is a strong relationship between muscle ability and endurance (the stronger muscles can exert effort for a longer period than the weak muscles. Consequently, the most important methods of improving endurance depend on the development of muscle strength). (Husam Al-Din et al, 1997: 95).

The researcher considers the method used (continuous descending pyramid) and the apparent gradual loading in the exercise through the set courses develop this physical ability. The theories of sport trainings emphasize "the gradation in the load of training because any increase in the training loads in terms of intensity and size is met with an increase in the functional ability of the internal organs ensuring the growth and development of the sport result' (Al-Mandalawi and Al-Shatti, 1987, 120).

The arithmetic mean for the set shot test for basketball wheelchair is 7.36 with a standard deviation of 2.157 . The mean value for the post-test is 8.909 with a standard deviation of 1.758 . The $(t)$ test for the independent samples is used to help in deciding to which test the changes benefit. From this test, the results indicate the presence of a real mean difference, because the calculated t value of them reaches 2.424 at the level of significance of $<.036$, so the statistical significance is mean and in favour of the Post test.

According to the researcher, the reason for this change is the nature of the performance of the set shot skill sample, since it requires from the player good physical capabilities in using a wheelchair. It is linked with the skill related performance. The mastery of skill performance of the wheelchair depends on extent of the development of the requirements in performance in terms of physical and mobility abilities. Darwish et al state that the physical characteristics directly impact the level of skill of the player, especially during the game (1998: 22). "In addition, the endurance component itself in its various forms contributes in mastering the defensive and forward skill work" (Darwish et al 1998: 19). Thus, the more strength and speed necessary to perform the movement under stress conditions the player endures, the more effective the performance is and without errors that may appear as a result of fatigue that negatively affects the skilful performance. 
Furthermore, the performance becomes more valid and does not include errors which appears because of tiresome which negatively affects the performance skill.

The tool used in the performance is the wheelchair that is an integral part of the player because of the nature of the game, as "the performance of mobility skills is closely related to the various aspects of physical characteristics. Thus, the good performance of mobility skills is not successful if it does not depend to a great extent on the required physical features" (Baqir and Zahir, 1987: 102).

\section{Results, analysis and discussion of the special strength and set shot}

Table 2 shows the lowest $r$ value for the real effect is 0.73 which is considered a big impact if we consider it in relation to Pearson formula (Al-Yasiri, et al, 2011: 209).

Table 2. Calculated t value and the real effect using Pearson formula.

\begin{tabular}{llcccc}
\hline Studied variables & Measure unit & $\mathrm{t}$ value & Size of effect ${ }^{\circledR}$ & Optimum value & Impact indication \\
\hline Explosive power & Meter & $3 / 171$ & $0 / 95$ &.$/ 50$ more than & big \\
Mobility speed & second & $3 / 306$ & $0 / 99$ &.$/ 50$ more than & big \\
Endurance capacity & minute & $6 / 095$ & $1 / 83$ &.$/ 50$ more than & big \\
Set shot & point & $2 / 424$ & $0 / 73$ &.$/ 50$ more than & big \\
\hline
\end{tabular}

1- The effect size is small if the value of $t$ is $0.10-0.29$.

2- The effect size is moderate if the value of $t$ 0.30-0.49.

3- The effect size is big if the value of $t$ is 0.50 - and above.

The value of $t$ in the tests discussed in the table above are $3.171-3.306-6.095-2.424$ in row. The real effect size using Pearson ${ }^{\circledR}$ equation are (0.95-0.99 - 1.83-0.73). It is greater than the optimum value that Pearson sets as more than 0.50 . Thus, the size of the effect is large for all variables discussed.

The researcher believes that the experimental research group is subject to the prepared method (continuous descending pyramid), which causes this effect on the differences in the post-test although a short period is used. Also, the important factors in this activity are strength, speed and endurance, so the exercises influence these physical capabilities because of their great importance in the game. Therefore, the established training curriculum influences these physical abilities, especially the endurance (it is said that the excessively repeated exercises with short period of intermittent rest result in the best effect on increasing the endurance of ability) (Hussam El-Din, 1993: 26).

The study agrees with Talha and believes that the load of exercise is a main tool to affect the progress of function of the body organs in training. This means that "training results in an increase of the ability of the individual for several days, weeks, and months and that is through the adaptations of body organs to perform these exercises" (Edigton and Edgerton,1976:8).

Jameel states that "this method is summarized by the fact that the player performs three overlapping sets without breaks. Each set is repeated six times and weights are lifted successively by the training colleagues. This this method is used for the purpose of changing the muscle patterns and its effects in order to continue growth and response" (Jamil, 2002: 103). 


\section{FINDINGS AND RECOMMENDATIONS}

\section{Findings}

1- The results show that the descending pyramid training has a positive effect on the development of the special strength of basketball players on wheelchairs.

2- The results indicate that the descending pyramid training positively effects on the development of the skill of set shot for wheelchair basketball players.

3- The results imply that there is a big and significant effect of descending pyramid training on the development of all research variables.

\section{Recommendations}

The study recommends the followings:

1. -The necessity to use descending pyramid training to develop forms of muscle strength.

2. -Avoiding this type of training during the general preparation period for the team.

3. -Conducting similar research involving physiological and physical variables and other games.

\section{REFERENCES}

Abdel-Fattah Ab., Ah.1997. Athletic Training (Physiological Foundations). Cairo: Dar Al-Fikr Al-Arabi for Printing and Publishing.

Abdel-Khaleq, I.1999. Athletic Training Theories and Applications. Cairo: Dar Al- Fikr Al-Arabi.

Abdul-Majeed, A. M. 1999. Tests, Measurement, and Evaluation in Physical Education. Amman: Dar AlFikr for Printing, Publishing, and Distribution.

Al-Basaty A., Ah. 2001. Physical and career training in football, planning, training, and measurement. Alexandria: The New University Publishing House.

Ali Ah., A., M. 2013. The effect of special exercises in developing endurance ability and kinesthetic perception and accuracy of the performance of some offensive skills for players of high classes in basketball on wheelchairs, unpublished PhD thesis. Babylon: University of Babylon/College of Physical Education.

Al-Ibrahim, Z., H., O. 2007. Building and legalizing a fitness test battery for wheelchairs (paralysis of lower limbs). Baghdad: University of Baghdad/College of Physical Education.

Al-Mandalawi and Al-Shatti, Q., H.1987. Training and Records. Mosul: University of Mosul/Directorate of Books.

Al-Qit, M., A. 1999. Jobs of Athletic Training Members. Cairo: Dar Al-Fikr Al- Arabi/First Floor.

Al-Yasiri, M., J., et al. 2011. the analytical statistic between theory and practice. 1st edition, Najaf AlAshraf: Al Dhiaa Printing Press.

Baqir, R., J. and Zahir, K., A. 1987. Basketball Technical Skills. Baghdad: Higher Education Press.

Darwish, K. et al. 1998. the physiological foundations of handball training (theories - applications).1st edition. Cairo: The Book Publishing Center.

Edigton D.W and Edgerton V. R.1967. the biology of physical activity. Boston: Houghton miffin company. Husam Al-Din, T.1993. Biomechanics, Theoretical and Applied Foundations. 1st edition. Cario: Dar AlFikr Al-Arabi.

Husam Al-Din, Talha et al 1997. The Scientific Encyclopedia in Training. The Book Center for Publishing. Jamil. M. 2002. Training in Body Building, Foundations and Rules. The Great Libyan Republic: House of Cultural Affairs.

Majeed, R., Kh. 1997. Applications in Physiology and Sports Training.Baghdad: 1st Floor, Dar Al-Shorouk for Publishing and Distribution. 


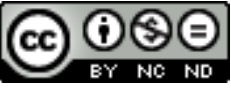

This work is licensed under a Attribution-NonCommercial-NoDerivatives 4.0 International (CC BY-NC-ND 4.0). 